\title{
GCU
}

Glasgow Caledonian

University

University for the Common Good

\section{Optimism as a candidate health asset: exploring its links with adolescent quality of life} in Sweden

Häggström Westberg, Katrin; Wilhsson, Marie; Svedberg, Petra; Nygren, Jens M.; Morgan, Antony; Nyholm, Maria

Published in:

Child Development

DOI:

$10.1111 /$ cdev. 12958

Publication date:

2019

Document Version

Author accepted manuscript

Link to publication in ResearchOnline

Citation for published version (Harvard):

Häggström Westberg, K, Wilhsson, M, Svedberg, P, Nygren, JM, Morgan, A \& Nyholm, M 2019, 'Optimism as a candidate health asset: exploring its links with adolescent quality of life in Sweden', Child Development, vol. 90 , no. 3, pp. 970-984. https://doi.org/10.1111/cdev.12958

\section{General rights}

Copyright and moral rights for the publications made accessible in the public portal are retained by the authors and/or other copyright owners and it is a condition of accessing publications that users recognise and abide by the legal requirements associated with these rights.

Take down policy

If you believe that this document breaches copyright please view our takedown policy at https://edshare.gcu.ac.uk/id/eprint/5179 for details of how to contact us. 


\section{Optimism as a candidate health asset: exploring its links with adolescent quality of life}

$\begin{array}{lcc}\text { Katrin Häggström Westberg } & \text { Marie Wihlsson } & \text { Petra Svedberg } \\ \text { Halmstad University, Sweden } & \text { Halmstad University, Sweden } & \text { Halmstad University, Sweden } \\ \text { Jens M Nygren } & \text { Antony Morgan } & \text { Maria Nyholm } \\ \text { Halmstad University, Sweden } & \text { Halmstad University, Sweden } & \text { Halmstad University, Sweden } \\ & \text { Glasgow Caledonian University, Scotland } & \end{array}$

Running title: Role of optimism as a candidate health asset

Corresponding author:

Maria Nyholm, PhD

School of Social and Health Sciences

Halmstad University

S-301 18 Halmstad

SWEDEN

Telephone: $+46-35167637$

Email: maria.nyholm@hh.se 


\begin{abstract}
This study aims to understand the role that optimism could play in the context of a health asset approach to promote adolescent health-related quality of life (HRQOL). Adolescents $(n=948)$, between 11 and 16 years old from a medium-sized rural town in Sweden answered questionnaires measuring optimism, pessimism and HRQOL. The findings indicate a significant decrease in optimism and a significant increase in pessimism between early and mid-adolescence. The study has allowed us to present associational evidence of the links between optimism and health-related quality of life. This infers the potential of an optimistic orientation about the future to function as a health asset during adolescence and by implication may provide additional intervention tool in the planning of health promotion strategies.
\end{abstract}

Keywords: Adolescence; family country background; Health related quality of life; Optimism; parent's marital status; Pessimism; Transition to adulthood.

\title{
Introduction
}

The sustainability of health and wellbeing for future generations relies in part on our ability to create the conditions necessary for the healthy growth and development of young people (Patel et al., 2007; Conversano et al., 2010). Early to mid-adolescence marks a particularly important time for families, schools, neighborhood and wider environments to ensure these conditions are set. Adolescence is a transitional stage of development between childhood and adulthood. It is also argued that health-related problems in adulthood seems too originate in adolescence, particularly between the ages of 11-18 (Kessler et al., 2005). The perceived 
physical, social and psychological changes and the transition itself influence adolescent's health-related quality of life (HRQOL) and wellbeing (Conversano et al., 2010; Eccles et al., 1993; Holmbeck et al., 1995). The most recent World Health Organization strategic document 'Investing in children: the European child and adolescent health strategy 2015-2020' (WHO, 2014) synthesized accumulated evidence that recognizes the many factors that can impact on their ability to do well during this crucial development period. These factors relate to their own genetic susceptibilities, to their family, to their environment (particularly school) and life events. The strategy argues that the challenge for policy is to strive for a balance between risk and protection activities so that young people can acquire the necessary skills and competences to secure them a productive and healthy life. In this way, young people will be more able to deal with growing academic expectations; changing social relationships with family and peers and physical and emotional changes associated with maturation. Marmot (2010) argues that policy responses that seek to maximize protective factors whilst minimizing risk factors accumulated over the life course can be successful in achieving health and wellbeing goals. In the context of young people's well being, Morgan (2010) proposed a health asset terminology and approach to support the development of an evidence base, which could support such activity.

A health asset approach has been defined as 'a system which creates positive paradigms for building the capacities of young people to be active in their own development and strengthens their ability to connect to a range of networks that facilitate health and wellbeing gains for themselves and for others' (Morgan \& Aleman-Diaz, 2016). It has two elements. The first is to understand through epidemiological research the ability of known potential health assets to explain different health-related outcomes. The second is to determine whether there is sufficient evidence for particular concepts to be useful in the practice of improving health and to find ways of translating the theoretical into a set of actions for change. 
This paper proposes the concept of optimism as a potential health asset and seeks to explore its association with a well-known proxy measure of well-being - Health Related Quality of Life (HRQOL). It provides a first step to understanding whether optimism can be put to practical use in the development, implementation and evaluation of health promotion programs.

\section{Identifying and understanding key health assets}

Whilst it would be naive to think that asset based approaches, can remove all the risks associated with young people growing up, strengthening protective factors in schools, at home and in local communities can make important contributions to reducing risk for the vulnerable (Rutter \& Smith, 1995, Fonagy \& Higgitt, 2000; Heijmens Visser et al., 2000, Morgan and Ziglio, 2007). For the purpose of this study health assets can be any resource that can ameliorate the effects of exposure to risk in a positive direction but can also operate in an additive protective way that still enables positive adaptations independent of risk exposure (Brooks et al., 2012; Morgan \& Ziglio, 2007). This definition and the development assets identified by the Search Institute (www.searchinstitute.org ) provide a useful framework for selecting a set of candidate assets that can be tested and developed as valid indicators to link and explain possible pathways to wellbeing. So far, assets have been classified into two broad types: external assets, those attained through positive relationships with others; and internal assets, the competencies and values that young people develop as a consequence of the social support and empowerment gained from the former (Benson et al., 2011). The concept of optimism in this context is included as an internal development asset. Optimistic young people have a positive view about their personal future which in turn helps them to secure healthy growth and development. The health asset framework calls for robust evidence that allows potential concepts (or candidate assets) to be tested through empirical research. This testing involves an iterative process to clarify definition and measurement so that health assets 
can be used in further empirical work to explain the phenomenon (HRQOL in this instance) of interest. This knowledge can then be used to inform health programmes. This study begins that process for the concept of optimism.

\section{Optimism: its conceptualization and measurement as a health asset}

Intuitively the concept of optimism has the potential to be a health asset as it can facilitate the achievement of wellbeing through positive thinking about the future. Benson et al (2011) have already identified it as one of 40 development assets for young people. More generally Lindstrom and Eriksson (2010) included it in their 'salutogenic umbrella' of concepts that are important in positively framing the delivery of health promotion programs. This paper has the intention to contribute to a better understanding of how optimism (and its associated concept, pessimism) can be included in a health asset approach and what issues need to be addressed in its further development.

There seem to be two prominent theoretical models of optimism defined in the literature; dispositional optimism (Carver \& Scheier, 2002) and attributive style optimism (Gillham \& Reivich, 2004; Orejudo et al., 2012). In the first model, dispositional optimism is described as the predisposition to expect positive outcomes when confronting major problems and having expectations that goals in the future will be attained (Scheier \& Carver, 1985). Dispositional optimism is thus a predictor of successful adaptation to stressful encounters, helping individuals to deal with problems in life rather than avoiding them and giving up (Carver \& Scheier, 2002). In contrast, the second model, attributive style optimism, is described as a pessimistic explanatory style where adolescents expect that they won't have the ability to control stressful events or create positive outcomes in life (Gillham \& Reivich, 2004).

Our ability to develop and utilize optimism as a health asset relies on good measurement. A number of studies have identified issues in the operationalization of both 
concepts (optimism and pessimism), which may have implications for measurement in health outcomes studies (Hertzberg et al., 2006; Nes \& Segerstrom, 2006). They can either be measured as two different concepts (bi-dimensional) or as opposite ends of a single range or continuum (uni-dimensional) (Nes \& Segerstrom, 2006). In measurement terms, different scales may assess different dimensions of the same phenomena or completely different phenomena depending on how the instruments have been operationalized. Dispositional optimism has been described as "the generalized expectancy that one will experience positive outcomes in life" (Magaletta \& Oliver, 1999) and has been studied among adolescents both as a bi-dimensional and a uni-dimensional construct. One of the first instruments in this area is the Generalized Expectancy for Success Scale (GESS) (Fischer \& Leitenberg, 1986), a bidimensional instrument that examines generalized future expectations for personal success and failure. Other instruments are the Optimism-Pessimism Test instrument (OPTI), a unidimensional instrument that examines general tendency to expect positive or negative outcomes (Stipek et al., 1981), and the Youth Life Orientation Test (Y-LOT) (Ey et al., 2005; Monzani et al., 2014), a bi-dimensional instrument that examines positive and negative general expectations.

This study uses the GESS instrument (in a larger questionnaire) as an objective measure of optimism and pessimism for assessing adolescent's future expectations. The advantage of GESS is that it focuses on future expectations for personal success and has been adopted for use as a self-report instrument among adolescents.

\section{The status of the evidence on optimism as a health asset}

There is no known research that explicitly explores the potential of optimism as a health asset. However a more general evidence base exists that highlights its links with a range of health related outcomes. Optimism has been commonly understood to be a protective factor in relation to health-related outcomes, although this relationship predominantly relates to adult 
populations (Carver et al., 2010; Conversano et al., 2010). Studies have demonstrated that high levels of dispositional optimism among adults relate to a wide range of positive wellbeing outcomes (Conversano et al., 2010; Scheier \& Carver, 1985), whereas lower levels have been associated with medical illness or health crises (Carver et al., 2010; Kurtz et al., 2008). Furthermore, individuals who have a pessimistic explanatory style more commonly use avoidance coping strategies (Folkman \& Lazarus, 1980; Rasmussen et al., 2006; Carver \& Scheier, 2014) and have more negative outcomes (Fibel \& Hale, 1978; Scheier \& Carver 1985; Strunk et al., 2006). Research has also shown that there is an inverse correlation between optimism and depressive symptoms and suicidal ideation among adults (Shang \& Sanna, 2001; Hart et al., 2008; Hirsch \& Conner, 2006; Van der Velden et al., 2007; Steele \& Wade, 2004). There are some adolescent studies that have shown positive correlations between optimism and health related outcomes (Alarcon et al., 2013; Bamford \& Lagatutta, 2012; Vacek et al., 2010; Ben-Zur, 2003), effective coping strategies and the adoption of good health behaviours (Jones et al. 2008) and better emotional functioning (Williams et al., 2010). As might be expected pessimistic orientations about the future have been shown to have the opposite effect on health outcomes for adolescents both in the general population (Reppucci et al., 1991; Strunk, 2006) and in health care (Sulkers et al., 2013; Williams et al., 2010). There are also some examples of optimism being used in health promotion intervention studies as an outcome but these have contradictory findings (Johnstone et al., 2014; Patton et al., 2011). These contradictions may suggest that our understanding of the protective aspects of optimism are not sufficiently well articulated for the idea to be translated into actions for practice. In part disentangling the concept has been complicated by the inextricable link to pessimism. For example, it has been argued that high levels of optimism can lead to an underestimation of health hazards whereas high levels of pessimism can be beneficial in preparing for unpredictable outcomes (Reppucci et al., 1991; Patton et al., 2011). 
Overall the body of published research available to assess the relationships between optimism and a range of health-related outcomes is varied. Much of it has been carried out in the context of healthcare settings studying such outcomes as surgery, cancer and heart disease and amongst adults. That said there is review level research that suggests that the relationship is positive (Carver et al., 2010; Carver \& Scheier, 2014). Although a study by Kurtz et al (2008), of patients with cancer found that optimism was negatively correlated with pain control. A recent review by Okado et al (2016) reviewed the role of optimism in pediatric cancer patients. They found that it was linked to fewer difficulties with pain, higher quality of life and stronger mental health functioning. In contrast, pessimism was associated with poorer outcomes in behavioral, physical and emotional functioning. The review did recognize however summarizing the data across studies was difficult due to definitional issues and design and methodological limitations. The field of optimism and mental health is also scattered. A review by (Conversano et al., 2010) however concluded that optimism has an important moderating role in the association between feelings of loss of hope and suicidal ideation. Carver and Scheier (2014) reviewed a range of epidemiological research that studied long-term prospective associations between optimism and health outcomes in large samples. Optimism was shown to have a relationship with social relations and social support. However it was recognized that this association could be tautological and that having strong social networks and social support could lead to someone being optimistic. Much of the work on optimism has taken place in health-related contexts, as people confront the transitions imposed by health crises. The early work shows that optimists fare better emotionally and psychologically than pessimists when confronting health problems.

Our study is set in the context of prevention, specifically to understand the skills, competences and attributes that are supportive (or protective) for healthy adolescent 
development. There is little or no research in this area. Although there are some examples of studies carried out amongst young people to look at the role of optimism in a range of health specific outcomes. For example, Wray et al (2013) studied the relationship between optimism and alcohol use amongst 14-18 years using a cross-sectional design. These results suggest that those who have more positive expectations of the future report lower levels of alcohol use at age 14, while those with more negative future perspectives report higher levels of alcohol use at that age. However they also found gender differences. Girls tended to be more optimistic than boys. Patten et al (2011) found positive associations between optimism and a range of emotional outcomes, substance abuse and anti-social behavior amongst early adolescents. The extent of the relationship also differed by gender. Carvajal (2012) found that optimism systematically decreased during early adolescence suggesting that is important to recognize the concept as dynamic and changing throughout the development years.

\section{The current study}

This study presents an opportunity to test and explore optimism as a health asset to promote wellbeing among adolescents. Specifically it uses data from a survey carried out in a medium sized rural town in southwest Sweden among 11-16 year old adolescents. We explore optimism and pessimism as a bi-dimensional construct and its impact on HRQOL among adolescents in two separate age groups (11-13 years and 14-16 years). The inclusion of these two age groups helped us observe differences that provide insights into issues relevant to this key transition stage (Holmbeck et al., 1995). Previous research has indicated age, gender and socio-demographic characteristics to have a potential impact on the relationship between

optimism and health-related outcomes (Biehl et al., 2014; Hutton et al., 2014; Meade \& Dowswell 2016; Orejudo et al., 2012). Measures were therefore included to control for these factors.

\section{Hypotheses}


Hypothesis 1 - there is an association between adolescent's self-rated optimism and pessimism and health related quality of life (HRQOL).

Hypothesis 2 - the association between adolescent's self-rated optimism and pessimism and HRQOL changes when gender and socio-demographic characteristics are taken into account.

\section{Methods}

Study Design

This study used data from a cross-sectional study in a medium-sized rural town in South West Sweden performed in 2011. For participant recruitment, pupils from junior high schools were invited to participate. The study included measures of HRQOL, optimism/pessimism and a range of proxy measures of socio economic status.

\section{Participants}

The sampling frame included pupils from seven municipal schools (from a total of 34 public and 4 private schools) selected on the basis of having a total of more than 100 pupils. Fifty classes were invited to participate in the study resulting in a sample of 24 classes with pupils aged 11-13 years old ( $\mathrm{n}=536$ pupils, younger age group) and 25 classes with pupils aged 1416 years old ( $\mathrm{n}=576$ pupils, older age group). One class (14-16 years) decided not to participate. For the purpose of this study we classified the younger age group as early adolescent and the older age group as mid-adolescent. A sample of 948 respondents $(n=467$ 11-13 years old and $n=481$ 14-16 years old) completed the questionnaires yielding a response rate of $87 \%$ and $84 \%$ respectively (non-respondents were almost exclusively due to absence from school during the day of data collection).

\section{Procedure}


Adolescents answered a self-report questionnaire consisting of two validated scales, one for measuring HRQOL and the other, concepts of optimism and pessimism. The Manchester Minneapolis Quality of Life instrument (MMQL) was used for the former and the Generalized Expectancy for Success Scale (GESS) for the latter. The adolescents were also asked to answer questions in relation to their socio-demographic characteristics (age, gender, parents marital status and family country background). Questionnaires were distributed to each class following a brief introduction by the researchers. Participants were also given the possibility to ask questions about the study or specific questions during completion of the questionnaire. Completed questionnaires were returned to the researchers by each respondent. However in two schools, teachers distributed and collected the questionnaires in return envelops from each class.

\section{Measures}

\section{Health related quality of life (HRQOL)}

The MMQL instrument exists in two forms which take account of the characteristics of two age groups, the MMQL-Youth form for 8-12 year olds and the MMQL-Adolescent form for 13-20 year olds (Bahitia et al., 2004; Einberg et al,. 2013). The MMQL-Youth form consists of four quality of life subscales; physical symptoms, physical functioning, psychological functioning and outlook on life comprising 32 items in total. The MMQL-Adolescent Form consists of seven quality of life subscales; physical functioning, cognitive functioning, psychological functioning, body image, social functioning, intimate relations and outlook on life with a total of 45 items. The items in the subscales of both forms were answered on a 4 or 5 point scale, with higher scores indicating better outcomes. Both versions of the instrument have good psychometric characteristics in terms of face and content validity, internal consistency (Cronbach's alpha from 0.88 to 0.92 ) and stability (ICC from $0.43-0.78$ ) and are available in versions translated in a Swedish context (Einberg et al., 2013). The MMQL 
instrument was selected to measure HRQOL based on that it has been shown to better capture the QOL perspective of health in comparison with other health status and QOL instruments developed for children (Fayed et al., 2011). Furthermore, the items used have a mainly positive phrasing, which is important for how each item is perceived and for the child's experience of contributing to the questionnaire (Fayed et al., 2011). Positively framing questions is also a pre-requisite of the health asset approach. The score for each individual item is based on the number of points in the scale; "Never" $=5$; "Seldom" $=4$, "Sometimes" $=3$, "Mostly" = 2 and "Always" = 1 . All items were summarized into a total score for the different age-groups. HRQOL was used both as a continuous variable (in multi-level analysis) and as a categorical variable (in logistic regression). Categorization was achieved according to the age-specific mean of HRQOL, were below mean was categorized as " 0 " and above mean as " 1 ".

\section{Optimism and Pessimism}

An age adapted version of the original GESS (Fibel \& Hale, 1976) was used to assess optimism and pessimism relevant to the study population (Fischer \& Leitenberg, 1986). The age adaptation of GESS included changes in the response options (from Likert scale to more simplistic true or false responses. Fischer \& Leitenberg (1986) based this age adaption decision on similar research with this age group and argue that this does not diminish the validity of the instrument. The age-adapted version includes 27 statements constructed with the same opening phrase; "In the future I expect that I will...". Sixteen items were phrased in the direction of success (optimism scale) and 11 items phrased in the direction of failure (pessimism scale). The optimism scale was scored using a range of 0-16 points, higher numbers indicating a higher level of optimism. The Cronbach's $\alpha$ for optimism in this study was 0.701 in the early adolescent group and 0.817 in the mid-adolescent group. The 
pessimism scale was scored with a range of 0-11 points, higher numbers indicating higher level of pessimism. The Cronbach's $\alpha$ for pessimism was 0.638 in the early adolescent group and 0.689 in the mid-adolescent group. It could be argued that there is an overlap between measures of optimism and pessimism and the Outlook of Life subscale in the MMQL scale, however assessment via Spearman correlation showed this not to be the case (Table 1). Furthermore, we found no collinearity between optimism and pessimism as indicated by Spearman s correlation test $(\mathrm{r}<.5)$ (Table 1). Optimism and pessimism were used both as a continuous variable (in multilevel analysis) and as a categorical variable (logistic regression).

\section{Insert Table 1}

\section{Socio-demographic characteristics}

Socio-demographic characteristics of participants were assessed early on in the questionnaire. Data relating to parental status were obtained from an initial section on socio-demographic characteristics. Adolescents were asked to answer questions on age, gender, parent's marital status and family country background. Gender was measured by the question "Are you a boy or a girl?" and the answer was coded girls (=1) and boys (=2). Parents' marital status was measured by the question "Are your parents divorced?" The answers were coded as 1 (=yes) and $0(=$ no). Family country background was measured by the question "Was your father born in Sweden?" and "Was your mother born in Sweden?". The answers were added together and then coded as both parents born in Sweden $(=0)$ and one or two parents born outside Sweden $(=1)$.

\section{Analytic Approach}

The two age groups were examined separately and statistical significance was assumed at $\mathrm{p}<0.05$. Mean (standard deviation) was used and numbers (proportions) for descriptive purpose. Chi-square, independent student t-tests and Mann-Whitney were conducted to 
compare MMQL, optimism, pessimism, gender, parent's marital status and family country background between age groups. We used SPSS statistics version 20.0 (IBM, New York, USA) and MPLUS version 7.2 (Muthen \& Muthen, Los Angeles, California) for statistical analyses. Multilevel models were used to analyze simple linear regression analysis with manifest variables in clustered data. The data was selected and clustered from seven different schools, where in the analysis the students represented level 1 and the school represented level 2. The degree of dependence of observation was measured by the intra-class correlation coefficient (ICC), using MPLUS. Our model included five manifest independent variables (gender, parents marital status, family country background, optimism and pessimism) and one manifest dependent variable (HRQOL).

In further analyses using SPSS and logistic regression, adolescents' school affiliation and cluster was adjusted for by including dummy variables for each school in the regression model (Rice \& Leyland, 1996). Multivariate logistic regression models were used to further calculate the associations between self-rated HRQOL, optimism and pessimism. Scores of self-rated HRQOL were dichotomized into above mean (high) scores below mean (low). In the regression models optimism scores and pessimism scores were categorized according to age-specific quartiles into four groups. Cut-off points in the early adolescents group were: 13 (q1- reference), 15 (q2), 16 (q3) in optimism and 0 (q1-low), 1 (q2), 3 (q3-reference) in pessimism. Cut-off points in the mid-adolescent group were: 14 (q1-reference), 15 (q2) and 16 (q3) in optimism and 0 (q1), 1 (q2) and 3 (q3-reference) in pessimism. Results were reported as odds ratios (OR) with $95 \%$ confidence intervals $(95 \% \mathrm{CI})$. Two multivariate models were used: the first model included gender as a covariate and the second model gender, parent's country background and marital status. 


\section{Missing data}

A number of 153 adolescents_(153) who had agreed to participate did not complete the total HRQOL. The extent of missing data on the statements of optimism and pessimism varied from $0.6 \%$ to $7.3 \%$ in the early adolescents group and $0.2 \%$ to $11.0 \%$ in the mid-adolescent group. On the socio-demographic characteristics variables (gender, parents marital status, family country background), the extent of missing data ranged from $0.6 \%$ to $3.0 \%$ in the early adolescents group and $0.2 \%$ to $2.5 \%$ in the mid-adolescents group. We used the full information maximum likelihood [FIML] approach to produce the maximum likelihood estimation of parameters using Mplus (Geiser, 2013).

\section{Ethical clearance}

The principal at each school approved participation in the study. Prior to data collection, each school distributed written information to children and their parents about the purpose and structure of the study, indicating that participation was voluntary and if children or their parents declined to participate, they could decide not to fill in the questionnaire without having to explain why. The participants were guaranteed anonymity. The study design was approved by the regional ethics committee in Lund (Dnr 2016-1003).

\section{Results}

Tables 2 and 3 summarize the descriptive statistics for HRQOL, optimism and pessimism, gender, parent's marital status and family country background by age group. The mean of total HRQOL was significantly lower $(\mathrm{p}<0.001)$ in the older age group (mean 3.87; SD: 0.39), compared with adolescents in the early adolescent group (mean 4.35; SD:0.37) (Table 2). 
Adolescents in both age groups were quite optimistic about their future, with high mean optimism and low mean pessimism scores (Table 3).

Insert table 2 and 3 here.

Table 4 presents the regression coefficient estimates from multilevel models. Since the interclass correlation was zero $(\mathrm{ICC}=0.000)$, which indicates that the variance between school (level 2) and HRQOL was negligible. We found that self-reported optimism was significantly associated and positively related to HRQOL within level (level 1) controlling for gender, parents marital status and family country background which means that adolescents in both age-groups which reported high levels of optimism were more likely to report higher levels of HRQOL than adolescents reporting lower levels of optimism Furthermore, in both age-groups, the students self-reported pessimism was significantly associated and negatively related to HRQOL within level (level 1) controlling for gender, parents marital status and family country background. This indicates that adolescents reporting high levels of pessimism were more likely to report a lower level of HRQOL than adolescents reporting lower levels of pessimism (table 4).

\section{Insert table 4 here}

Table 5 presents odds ratio with $95 \%$ confidence interval of the likelihood of rating high HRQOL in different levels of optimism and pessimism. The association between high levels of optimism and high self-rated HRQOL was significant in the early adolescent group $(\mathrm{OR}=4.02 ; 95 \% \mathrm{CI}: 1.27-3.87 ; \mathrm{p}=.01)$ and in the mid-adolescent group $(\mathrm{OR}=2.63 ; 95 \% \mathrm{CI}$ : $1.50-4.60 ; \mathrm{p}=<.001)$ compared to low levels of optimism. This association was stable after adjusting for gender, parent's marital status and family country background in both age groups. Adolescents with low pessimism were more likely to rate high HRQOL, in the early 
adolescents group $(\mathrm{OR}=3.30 ; 95 \% \mathrm{CI}: 1.73-6.28 ; \mathrm{p}=<.001)$ and in the mid-adolescents group $(\mathrm{OR}=4.69 ; 95 \% \mathrm{CI}: 1.74-5.44 ; \mathrm{p}=<.001)$. These associations remained significant when adjusting for gender, parent's marital status and family country background both in the early in adolescent group $(\mathrm{OR}=3.36$; 95\% CI: 1.67-6.65; $\mathrm{p}=<.001)$ and in the mid-adolescent group $(\mathrm{OR}=4.62 ; 95 \% \mathrm{CI}: 2.07-10.31 ; \mathrm{p}=<.001)$.

\section{Insert table 5 here}

\section{Discussion}

This study provides associational evidence that optimism has a protective relation to HRQOL during adolescence among pupils from junior high schools in a medium-sized rural town in South West Sweden. The sample included pupils from seven municipal schools based on a geographical distribution of these schools in the town environment and broad sociodemographic representation of the inhabitants. The pupils in this study can be seen as representative of those living in typical rural towns in Sweden. The intention of the study was to contribute to our understanding of the utility of optimism as a health asset for promoting wellbeing among adolescents. The process of doing so cannot be achieved in one study as the assessment of candidate assets needs to accumulate across studies in different contexts and population groups. This study does suggest however, based on associations that optimism can be protective for low HRQOL and the relationship is stable (in both age groups) even after controlling for gender and selected socio-demographic indicators (parent's marital status and family country background). In contrast, it is suggested that high levels of pessimism were a risk factor for rating low HRQOL and the relationship was similarly robust after taking confounding factors into account. Overall, the findings support our first hypothesis that there is an association between adolescent's self-rated optimism and pessimism and HRQOL. 
Early and mid-adolescence

The findings from this study indicate a significant decrease in optimism and a significant increase in pessimism between early and mid-adolescence, which is in line with other research (Patton et al., 2011). The changes seen in optimism and pessimism are interesting from a transitional and developmental perspective. There are multiple challenging transitions during the period of adolescence, for example onset of puberty and change of schools. From a developmental perspective we know that from the age of seven, children generally have a capability to use a range of coping strategies to deal with negative emotions (Bamford \& Lagattuta, 2012; Holmbeck et al., 1995). Fischer and Leitenberg (1986) conclude that children in early adolescence are generally more optimistic than pessimistic about their long-term future. Patton et al. (2011) found that optimism generally decreases with age (12-14 years compared to two years later) and this was particularly pronounced among girls. However, interestingly a study of pre-university students (mean age of 18.2 years) found that by this age expectancy for success in the future had increased (Yong, 2010). A possible explanation for the findings in our research and in other studies might be that those at the stage of early adolescence may not have been exposed to life expectations, perceived life chances and attaining goals and are therefore more likely to be optimistic. In contrast, those at the stage of mid-adolescence are more likely to be less optimistic about the future because of various transitions and accumulated stressful life events. However, as already stated it seems that as adolescents progress through this development period, they eventually re-gain a sense of optimism (Young, 2010).

The resurgence of optimism could be the result of cumulative exposure to significant positive life experiences and the acquirement of good experiences of coping with new life events. Adolescents' opportunities of acquiring good experience of coping with new life events can be expected to play an important role in the development of an optimistic 
outlook about personal future (Carver et al., 2010; Wrosch \& Scheier, 2003). Effective coping strategies among adolescents involve a capability of adjusting one's goals to certain demands. Individuals with higher levels of optimism have displayed greater flexibility in coping and goal pursuit (Carver et al., 2010; Wrosch \& Scheier, 2003; Hanssen et al., 2014). In other words, being able to switch flexibly between different coping strategies might be a capacity, facilitated by an optimistic orientation, that separates, distinguishes and influences the HRQOL of adolescents.

The changes in levels of optimism across the adolescent development years highlight the need for more clarity about the definition of optimism, if it is to be put to use for practical purpose. For example, Carver (2014) suggests that dispositional optimism is a personality trait that is relatively stable, however he does concede that changing a person's outlook on life can be done but it is not a simple matter. One of the pre-requisites of applying concepts using an asset approach is that they can be clearly defined. Further work to clarify these definitional issues in the context of adolescence is still required.

\section{Gender and socio-demographic characteristics}

The findings from our study indicate that gender had an impact on the relationship between optimism and pessimism and HRQOL, whereas the socio-demographic characteristics did not. Therefore, this study's results do not support our second hypothesis and is contradictory to earlier research (Biehl et al., 2014; Orejudo et al., 2012). However, the complexities of the relationships might require further work in different adolescence populations in Sweden and other countries in order to consolidate whether this is true or not.

Findings support wider literature in suggesting that gender has an impact on health related outcomes (Deptula et al., 2006; Orejudo et al., 2012; Patton et al., 2011). The 
role of gender and optimism at different ages should be further investigated to increase the understanding of the factors that contribute to the development of optimism. Contrary to expectations, our findings did not show that sociodemographic characteristics have an impact on the relationship between optimism and pessimism and HRQOL. Other research, has proposed that optimism can act as a buffer for negative health outcomes associated with poor socioeconomic status (Adler, 2007; Carver et al., 2010; Finkelstein et al., 2007; Piko et al., 2012). It has also been suggested that such a relationship might be explained by the adolescents' family environment. For example, an adolescents' capability of positive thinking may depend more on: levels of parental optimism (Bamford \& Lagatutta, 2012), parents' ability to deliver an optimistic approach to their children (Bamford \& Lagatutta, 2012; Orejudo et al., 2012) and a good relationship and communication with parents (Ben-Zur, 2003; Korkeila et al., 2004; Orejudo et al., 2012). That is an adolescents general social environment may be at least as important as the actual socioeconomic status of the family. The relative impact that different dimensions of an adolescent's social environment can have on optimism and its potential subsequent health benefits is worthy of further study.

\section{Implications for research, policy and practice}

This study was placed with a health asset framework as it aspired to provide a possibility of translating the research findings into practice. It demonstrated that the concept of optimism has the potential to be a health asset given the positive associations found between it and HRQOL. However, in order to put it to practical use in policy and practice, work is required to further understand how best to define and measure it. This will provide more clarity on how to gain more evidence about how optimism can link and explain a range of antecedents along the pathway to adolescent health and wellbeing. The health asset approach places emphasis on 
the building of theory in order to advance this understanding as it is argued that theory based programs are more likely to be effective (Garcia-Moya \& Morgan, 2016). In order to be useful to the asset approach such theories need to be positively framed. It has already been suggested that the concept of optimism has this potential (Erikson \& Lindstrom, 2010). However, the idea of optimism needs to move from a concept with potential to a theoretically based framework for action in health promotion orientated towards adolescents. There are a number of specific areas to explore that in the first instance are best suited to review level research. Such work would: explore the theoretical underpinnings of optimism and the implications for its definition and measurement; synthesize the current knowledge about the links between optimism and a range of health related outcomes; and identify the types of environmental factors that can encourage adolescents to be optimistic about the future. This would support the advancement of optimism as an explanatory theory for improving adolescent wellbeing so that it can be useful to both elements (described in the introduction) of the health asset approach. Until this work is completed, we argue that the field of optimism research is insufficiently developed for utilization in intervention studies and its translation into policy and practice.

\section{Strengths and limitations}

The obvious limitation of this cross-sectional study (inherent in all cross-sectional designs) is its weakness in establishing causal mechanisms as this can only be inferred. Thus, it is difficult to rule out if adolescents with greater HRQOL tend to be more optimistic or the other way around. Therefore, our research questions are more ideally suited to longitudinal designs, which can explore the direction of relationships between variables. That said cross section analysis is important in helping to better formulate future research questions. An additional 
potential limitation relates to sampling. The seven schools were not randomized selected, instead the selection were based on the need to be large enough to avoid potential identification of individual adolescents in the data as well as to achieve representation of the town's various geographic and sociodemographic areas. .The ICC indicated that the variance between school and HRQOL was negligible.

There are a number of strengths to the study. Firstly the response rate in both age groups of adolescents was high. In addition the instruments used are internationally established, validated and commonly used measures of optimism and pessimism and HRQOL. The versions of both the GESS instrument and HRQOL used were also adapted and fit for purpose amongst children and adolescents. The GESS instrument did however compel respondents to answer in a dichotomous way (forced), which could be argued as an additional weakness, contributing to small variations in ratings of optimism and pessimism and influence the statistical analysis. The study was based upon self-reported data, which strengthens the results as it is based on an adolescents own perception of their HRQOL, optimism and pessimism.

\section{Conclusions}

The study has allowed us to present associational evidence of the links between optimism and health-related quality of life in a context of a medium-sized rural town in Sweden. The findings indicate a significant decrease in optimism and a significant increase in pessimism between early and mid-adolescence. Gender had an impact on the relation between optimism and pessimism and HRQOL, whereas the socio-demographic characteristics did not. This infers the potential of an optimistic orientation about the future to function as a health asset during adolescence and by implication may provide additional intervention tool in the 
planning of health promotion. However, further work is required to articulate optimism as a health asset and a concept with practical implication. 


\section{References}

Adler, N.E., (2007). Editorial; Health disparities: What's optimism got to do with it? Journal of Adolescent Health, 40, 106-107.

Alarcon, G. M., Bowling, N. A., \& Khazon, S. (2013). Great expectations: a meta-analytic examination of optimism and hope. Personality and Individual Differences, 54, 821-827.

Bamford, C., \& Lagattuta, K.H. (2012). Looking on the bright side: children's knowledge about the benefits of positive versus negative thinking. Child Development, 83, 667-682.

Biehl, A., Hovengen, R., Grøholt, E.K., Hjelmesæth, J., Strand, B.H., \& Meyer, H.E. (2014). Parental marital status and childhood overweight and obesity in Norway: a nationally representative cross-sectional study. BMJ Open, 4:e004502. doi: 10.1136/bmjopen-2013-004502.

Benson, P.L., Scales, P.C., \& Syvertsen, A.K. (2011). The contribution of the developmental assets framework to positive youth development theory and practice. In: R.M. Lerner, J.V. Lerner, \& J.B. Benson (eds.), Advances in Child Development and Behavior, 41, 195-228.

Ben-Zur, H. (2003). Happy Adolescents: The Link Between Subjective Well-Being, Internal Resources, and Parental Factors. Journal of Youth and Adolescence. 32, 67-79.

Bhatia, S., Jenney, M.E.M., Wu, E., Bogue, M.K., Rockwood, T.H., Feusner, J.H., Friedman, D. L., Robison, L. L., Kane, R.L. (2004). The Minneapolis-Manchester 
quality of life instrument: reliability and validity of the youth form. Journal of Pediatrics,45, 39-46.

Brooks F., Magnusson J., Spencer N and Morgan A. (2012). Adolescent Multiple Risk Behaviour: An Assets Approach To The Role Of Family, School And Community. Journal of Public Health, 34 , Suppl 1. 34-56.

Carvajal, S. C. (2012). Global positive expectancies in adolescence and healthrelated behaviours: Longitudinal models of latent growth and cross-lagged effects. Psychology and Health, 27, 916-937.

Carver, C.S., \& Scheier, M.F. (2014). Dispositional optimism. Review. Trends in cognitive Sciences, 18, 293-299.

Carver, C.S., Scheier, M.F., \& Segerstrom, S.C. (2010). Optimism. Clincial Psychology Review, 30, 879-889.

Chang, E.C., \& Sanna, L.J. (2001). Optimism, pessimism, and positive and negative affectivity in middle-aged adults: a test of a cognitive-affective model of psychological adjustment. Psychology and Aging, 16, 524-31.

Conversano, C., Rotondo, A., Lens,i E., Della, Vista, O., Arpone, F., \& Reda, M. A. (2010). Optimism and Its Impact on Mental and Physical Well-Being. Clincial Practice \& Epidemiology in Mental Health, 6, 25-29.

Deptula, D., Cohen, R., Phillipsen, L., \& Ey, S. (2006). Expecting the best: The relation between peer optimism and social competence. Journal of Positive Psychology, 1, 130-141. 
Eccles, J.S., Midgley, C., Wigfield, A., Buchanan, C.M., Reuman, D., Flangan, C., \& Iver, D.M. (1993). The impact of stage-environment fit on young adolescents' experience in schools and families. American Psychologist, 48, 98-101.

Einberg, E.L., Kadrija, I., Brunt, D., Nygren, J.N., \& Svedberg, P. (2013) .

Psychometric evaluation of a Swedish version of Minneapolis-Manchester quality of life- youth form and adolescent form. Health and quality of life outcomes, 11, doi: 10.1186/1477-7525-11-79.

Ey, S., Hadley, W., Allen, D., Palmer, S., \& Klosky, J. (2005). A new measure of children's optimism and pessimism: The youth orientation test. Journal of Child Psychology and Psychiatry, 46, 548-558.

Fayed, N., Schiariti, V., Bostan, C., Cieza, A., \& Klassen, A. (2011). Health status and QOL instruments used in childhood cancer research: deciphering conceptual content using world health organization definitions. Quality of Life Research, 20:1247-1258.

Fibel, B., \& Hale, W.D. (1978). The Generalized Expectancy for Success Scale A New Measure. Journal of Consulting and Clincal Psychology, 46, 924-31.

Fischer, M., \& Leitenberg, H. (1986). Optimism and Pessimism in Elementary School-Aged Children. Child Development, 57, 241-248.

Finkelstein, D.M., Kubzansky, L.D., Capitman, J.A., \& Goodman, E. (2007). Socioeconomic differences in adolescents stress. The role of psychological resources. Journal of Adolescent Health, 40,127-34.

Folkman, S., \& Lazarus, R.S. (1980). An analysis coping in a middle aged community sample. Journal of Health and Social Behaviour, 21, 219-239. 
Fonagy P, Higgitt A. (2000) An attachment theory perspective on early influences on development and social inequalities. In Osofsky J, Fitzgerald H, editors. WAIMH Handbook of Infant Mental Health (pp. 521-560). New York, John Wiley.

Geiser, G. (2013). Dataanalysis with MPLUS. New York; Guilford.

Gillham, J. \& Reivich, K. (2004). Cultivating Optimism in Childhood and Adolescence. The ANNALS of the American Academy of Political and Social Science, 591, 146-163. 44, $36-46$.

Hanssen, M.M., Vancleef, L.M.G., Vlaeyen, J.W.S., Hayes, A.F. Schouten, E.G.W., \& Peters M.L. (2015). Optimism, Motivational Coping and Well-being: Evidence Supporting the Importance of Flexible Goal Adjustment. Journal Happiness Studies, 16, 1525-1537.

Hart, S.L., Vella, L., \& Mohr, D.C. (2008). Relationships among depressive symptoms, benefit-finding, optimism, and positive affect in multiple sclerosis patients after psychotherapy for depression. Health Psychology, 27,230-238.

Heijmens Visser, J., Van Der Ende, J., Koot, H.M., \& Verhulst, F.C. (2000). Predictors of psychopathology in young adults referred to mental health services in childhood or adolescence. British Journal of Psychiatry, 177, 59-65.

Hirsch, J.K., \& Conner, K.R. (2006). Dispositional and explanatory style opti mism as potential moderators of the relationship between hopeless- ness and suicidal ideation. Suicide and Life-Threatening Behavior, 36, 661-669. 
Holmbeck, G.N., Paikoff, R.L., \& Brooks-Gunn, J. (1995). Parenting adolescents. In: Bornstein MH, editor. Handbook of parenting: Vol. 1. Children and parenting. Hillsdale, NJ: Erlbaum.

Hutton, K., Nyholm, M., Nygren, J.M., \& Svedberg, P. (2014). Self-rated mental health and socio-economic background: a study of adolescents in Sweden. BMC Public Health, doi: 10.1186/1471-2458-14-394.

Hertzberg, P., Glasmer, H.J., \& Hoyer, J. (2006). Separating optimism and pessimism: A robust psychometric analysis of the revised life orientation test (LOT-R). Psychological Assessment, 18, 433-438.

IBM Corp. Released 2011. IBM SPSS Statistics for Windows, Version 20.0. Armonk, New York: IBM Corp.

Jones, T., DeMore, M., Cohen, L.L., O'Connell, C., \& Jones, D. (2008). Childhood healthcare experiences healthcare attitudes and optimism as predictor of healthcare behaviour. Journal of Clinical Psychology in Medical settings, 15, 234-240.

Johnstone, J., Rooney, R.M,, Hassan, S., \& Kane, R.T.(2014). Prevention of depression and anxiety symptoms in adolescents: 42 and 54 months follow-up of the Aussie Optimism Program-Positive Thinking Skills. Frontiers in Psychology, 5, doi: 10.3389/fpsyg.

Kessler, R.C., Berglund, P., Demler, O., Jin, R., Merikangas, K.R., \& Walters, E.E. (2005). Lifetime prevalence and age-of-onset distributions of DSM-IV disorders in the National Comorbidity Survey Replication. Archives of general psychiatry, $62,593-602$. 
Korkeila, K., Kivela, L., Suominen, S., \& Batear, J. (2004). Childhood adversities, parent-child relationships and dispositional optimism in adulthood. Social Psychiatry Epidemiology, 39, 286-292.

Kurtz, M. E., Kurtz, J. C., Given, C. W., \& Given, B. A. (2008). Patient optimism and mastery- do they plan a role in cancer patients' management of pain and fatigue? Journal of Pain and Symptom Management, 36, 1-10.

Lindstrom, B., \& Ericsson M. (2010). A salutogenic approach to tackling health inequalities. In Morgan, Davies and Ziglio (Ed.), Health assets in a global context (pp.17-58). New York, Springer.

Magaletta, P. R., \& Oliver, J. M. (1999). The hope construct, will, and ways: Their relations with self-efficacy, optimism, and general well-being. Journal of Clinical Psychology, 55, 539- 551.

Marmot M. (2010). Fair Society, Healthy Lives: The Marmot Review. Strategi Review of Health Inequalitites in England post-2010. London: Strategic Review of Health Inequalities.

Meade, T., \& Dowswell, E. (2016). Adolescent's' health-related quality of life (HRQoL) changes over time: a three year longitudinal study. Health and Quality of Life Outcomes, doi: 10.1186/s12891-015-0713-0.

Monzani, D., Steca, P., \& Greco, A. (2014). Brief report: Assessing dispositional optimism in adolescence--factor structure and concurrent validity of the Life Orientation Test-Revised. Journal of Adolescence, 37, 97-101. 
Morgan, A. (2010). Social capital as health assets for young people's health and wellbeing.Journal of child and adolescent Psychology, Supplement 2 life contexts, 19-42.

Morgan, A. (2014). Revisiting the Asset Model: a clarification of ideas and terms. Global Health Promotion, 21, 3-6.

Morgan, A., \& Aleman-Diaz, D. (2016). Measuring what matters for young people's health and well-being: an asset approach what matters. Learning for Wellbeing Magazine, Vol 1 chapter 2. Available at: https://www.14wb-magazine.org/

Morgan, A., \& Ziglio, E. (2007). Revitalising the evidence base for public health: an assets model. Promotion \& education, Suppl 2, 17-22.

Monzani, D., Steca, P., \& Greco, A. (2014). Brief report: Assessing dispositional optimism in adolescence--factor structure and concurrent validity of the Life Orientation TestRevised. Journal of Adolescence, 37, 97-101.

Muthén and Muthén, (1998-2015). Mplus user's guide (7th ed.) Muthén \& Muthén Los Angeles, CA (1998-2015).

Nes, L. S., \& Segerstrom, S.C. (2006). Dispositional optimism and coping: a meta-analytic review. Personality and Social Psychology Review, 10, 235-251.

Okado, Y., Howard Sharp, K.M., Tillery, R., Long, A.M., \& Phipps, S. (2016). Profiles of Dispositional Expectancies and Affectivity Predict Later Psychosocial Functioning in Children and Adolescents With Cancer. J Pediatr Psychol. 41, 298-308. doi: 10.1093/jpepsy/jsv096. 
Orejudo, S., Puyuelo, M., Fernandéz-Turrado ,T., \& Ramos,T. (2012). Optimism in adolescence: A cross-sectional study of the influence of family and peer group variables on junior high schools students. Personality and Individual Differences, 52, 812-817.

Rice, N., \& Leyland, A. (1996). Multilevel models: applications to health data. Journal of Health Services Research \& Policy, 1(3)154-164.

Rutter, M., \& Smith, D.J. (Eds). (1995) Psychosocial disorders in young people. Time trends and their causes. Chichester; John Wiley \& Sons.

Patel, V., Flisher, A.J., Hetrick S., \& McGorry, P. (2007). Mental health of young people; a global public-health challenge. Lancet, 369, 1302-1313.

Patton, G.C., Tollit, M.M., Romaniuk, H., Spence, S.H., Sheffield, J., \& Sawyer, M.G. (2011). A Prospective Study of the Effects of Optimism on Adolescent Health Risks. Pediatrics, 127, 308-16.

Piko B.F.,LuszczynskaA., \& Fitzpatrick, K.M. (2012). Social inequalities in adolescent depression: The role of parental social support and optimism. International Journal of Social Psychiatry, 59, 474-481.

Rasmussen, H.N., Wrosch, C., Scheier, M.F., \& Carver, C.S. (2006). Self-regulation processes and health: the importance of optimism and goal adjustment. Journal of Personality, 74, 1721-1747.

Rice, N., \& Leyland, A. (1996): Multilevel models: applications to health data. Journal of Health Services Research \& Policy, 1, 154-164. 
Reppucci, J.D., Revenson, T.A., Aber, M., \& Reppucci, N.D., (1991). Unrealististic optimism among adolescent smokers and nonsmokers. Journal of Primary Prevention, 11, 227236.

Scheier, M.F., \& Carver, C.S. (1985). Optimism, coping, and health: assessment and implications of generalized outcome expectancies. Health Psychology, 4, 219-47.

Steele, A., \& Wade, T.D. (2004).The contribution of optimism and quality of life to depression in an acute coronary syndrome population. European Journal of Cardiovascular Nursing, 3, 231-7.

Stipek, D.J., Lamb, M.E., \& Zigler, E.F. (1981). OPTI: a measure of children's optimism. Educational and Psychological Measurement, 41, 131-143.

Strunk, D. R., Lopez, H., \& DeRubeis, R. J. (2006). Depressive symptoms are associated with unrealistic negative predictions of future life events. Behaviour Research and Therapy, 44, 861-882.

Sulkers, E., Fleer, J., Brinksma, A., Roodbol, P.F., Kamps ,W.A., Tissing, W.J.E. Sanderman, R. (2013). Dispositional optimism in adolescents with cancer: Differential associations of optimism and pessimism with positive and negative aspects of well-being. British Journal of Health Psychology, 18, 474-489.

Vacek, K. R., Coyle, L.D., \& Vera, E.M. (2010). Stress, self-esteem, hope, optimism, and well-being in urban, ethnic minority adolescents. Journal of Multicultural Counseling and Development, 38, 99-111. 
Van der Velden, P.G., Kleber, R.J., Fournier, M., Grievink, L., Drogendijk, A., \& Gersons, B.P. (2007). The association between dispositional optimism and mental health problems among disaster victims and a comparison group: a prospective study. Journal of Affective Disorders, 102, 35-45.

Williams, N., Davis, G., Hancock, M., \& Phipps, S. (2010). Optimism and Pessimism in Children with Cancer and Healthy Children: Confirmatory Factor Analysis of the Youth Life Orientation Test and Relations with Health-Related Quality of Life. Journal of Pediatric Psychology, 35, 672-682.

WHO (2014) Investing in Children: the European Child and Adolescent Strategy 2015-2020. WHO Regional Office for Europe, Copenhagen.

Wray, T.B., Dvora, R.D. Hsia, J.F., Arens, A.M., \& Schweinle, W.E., (2013). Optimism and Pessimism as Predictors of Alcohol Use Trajectories in Adolescence. Journal of Child \& Adolescent Substance Abuse, 22, 58-68, DOI: $10.1080 / 1067828 X .2012 .729915$

Wrosch, C., \& Scheier, M.F. (2003). Personality and quality of life: The importance of optimism and goal adjustment. Quality of Life Research, 12, 59-72.

Yong, F.L. (2010). A Study on the Self-Efficacy and Expectancy for Success of Pre-University Students European Journal of Social Sciences, 13(4), 514-524. 


\section{Table 1}

Correlation between optimism, pessimism and dimension of HRQOL- outlook of life.

\section{Optimism Pessimism}

\begin{tabular}{lcc} 
& $\mathrm{r}$ & $\mathrm{r}$ \\
\hline Early adolescence group & & \\
Outlook of life & $.10^{\mathrm{a}}$ & $-.09^{\mathrm{a}}$ \\
Optimism & - & $-.37^{\mathrm{a}}$ \\
Pessimism & $-.37^{\mathrm{a}}$ & - \\
Mid-adolescence group & & \\
Outlook of life & $.24^{\mathrm{a}}$ & $-.23^{\mathrm{a}}$ \\
Optimism & - & $-.44^{\mathrm{a}}$ \\
Pessimism & $-.44^{\mathrm{a}}$ & - \\
& & \\
\hline
\end{tabular}

${ }^{a}$ Based on spearman correlation (r). All correlation coefficients are significant $\mathrm{p}<.05$. 
Table 2

Mean (SD) in HRQOL total scores and in diffrent dimensions of HRQOL in early adolescence group and in mid-adolescence group.

\begin{tabular}{|c|c|c|c|c|c|c|c|c|c|}
\hline & & $\begin{array}{l}\text { arly ac } \\
(\mathrm{n}=467\end{array}$ & escence gr & & & $\begin{array}{l}\text { id-ad } \\
\mathrm{n}=48\end{array}$ & cence gro & & \\
\hline & mean $^{\mathrm{a}}$ & $(\mathrm{SD})$ & $\begin{array}{l}\text { minimum } \\
\text { scores }\end{array}$ & $\begin{array}{c}\text { maximum } \\
\text { scores }\end{array}$ & mean & $(\mathrm{SD})$ & $\begin{array}{c}\text { minimum } \\
\text { scores }\end{array}$ & $\begin{array}{l}\text { maximum } \\
\text { scores }\end{array}$ & $\mathrm{P}^{\mathrm{b}}$ \\
\hline HRQOL total score & 4.35 & 0.37 & 2.71 & 5.00 & 3.87 & 0.39 & 1.73 & 4.69 & $<.001$ \\
\hline The diffrent dimensions of $H$ & & & & & & & & & \\
\hline Physical function & 4.19 & 0.59 & 2.29 & 5.00 & 3.87 & 0.57 & 1.00 & 5.00 & $<.001$ \\
\hline Psychological function & 4.08 & 0.55 & 2.13 & 5.00 & 3.95 & 0.59 & 1.00 & 5.00 & .002 \\
\hline Outlook of life & 4.47 & 0.52 & 2.19 & 5.00 & 4.10 & 0.83 & 1.00 & 5.00 & $<.001$ \\
\hline Physical symptoms & 4.52 & 0.33 & 2.88 & 5.00 & $\mathrm{c}$ & & & & \\
\hline Body image & c & & & & 3.98 & 0.68 & 1.13 & 5.00 & \\
\hline Social function & c & & & & 4.28 & 0.64 & 1.00 & 5.00 & \\
\hline Intimate relations & c & & & & 4.10 & 0.75 & 1.25 & 5.00 & \\
\hline Cognitive function & c & & & & 3.27 & 0.25 & 2.33 & 4.22 & \\
\hline
\end{tabular}

Missing data (early adolescence, mid adolescence): HRQOL total score (67, 84), physical function (19,19), psychological function (27,33), outlook of life (30, 12), ohysical symptoms (26, a), body image (a, 28), social function (a,16), intimate relations (a,18) and cognitive function (a,28).

The mean was based on: all items in the MMQL instrument were summarized and dividing by the number of items into a total score.

Based on t-test, $\mathrm{p}<.05$

Missing value due to differences in MMQL version according to age. 
Table 3

Optimism, pessimism and socio-demographic characteristics in early adolescence group and in midadolescence group.

$$
\begin{aligned}
& \text { Early adolescence group Mid-adolescence group } \\
& (\mathrm{n}=467) \quad(\mathrm{n}=481)
\end{aligned}
$$

\begin{tabular}{|c|c|c|c|c|c|c|c|c|c|}
\hline & mean & (SD) & $\begin{array}{c}\text { minimum } \\
\text { scores }\end{array}$ & $\begin{array}{c}\text { maximum } \\
\text { scores }\end{array}$ & mean & (SD) & $\begin{array}{l}\text { minimum } \\
\text { scores }\end{array}$ & $\begin{array}{c}\text { maximum } \\
\text { scores }\end{array}$ & $\mathbf{p}^{\mathbf{a}}$ \\
\hline \multicolumn{10}{|l|}{ GESS } \\
\hline $\begin{array}{l}\text { Optimism } \\
\text { sumscore }\end{array}$ & 14.42 & $(2.12)$ & 2 & 16 & 13.93 & $(1.00)$ & 1 & 16 & 0.017 \\
\hline $\begin{array}{l}\text { Pessimism } \\
\text { sumscore }\end{array}$ & 1.53 & $(1.72)$ & 0 & 10 & 1.93 & $(1.96)$ & 0 & 11 & 0.006 \\
\hline $\begin{array}{l}\text { Socio- } \\
\text { demographic } \\
\text { characteristic }\end{array}$ & $\mathbf{n}$ & $(\%)$ & & & $\mathbf{n}$ & $(\%)$ & & & $\mathbf{P}^{\mathbf{d}}$ \\
\hline \multicolumn{10}{|l|}{ Gender } \\
\hline Girls & 229 & $(49.4)$ & & & 227 & $(47.2)$ & & & .51 \\
\hline Boys & 235 & $(50.6)$ & & & 254 & $(52.8)$ & & & \\
\hline \multicolumn{10}{|c|}{$\begin{array}{l}\text { Parents' marital } \\
\text { status } \\
\text { Divorced parents }\end{array}$} \\
\hline No & 316 & $(69.6)$ & & & 322 & $(68.1)$ & & & .62 \\
\hline Yes & 138 & $(30.4)$ & & & 151 & (31.9) & & & \\
\hline \multicolumn{10}{|c|}{$\begin{array}{l}\text { Family country } \\
\text { background } \\
\text { One or two parents born } \\
\text { outside Sweden }\end{array}$} \\
\hline No & 282 & $(62.3)$ & & & 296 & $(63.0)$ & & & .82 \\
\hline Yes & 171 & (37.7) & & & 174 & $(37.0)$ & & & \\
\hline $\begin{array}{l}\text { Missing data (early } \\
\text { marital status ( } 13,9 \\
\text { and family country } \\
(14,12) \text {. } \\
\text { a Based on Mann } \\
\text { Witney, }<<0.05 \text {. } \\
\text { b Based on } X^{2} \text { test, } \\
\text { p }<0.05\end{array}$ & $\begin{array}{l}\text { escence/m } \\
\text { ground }\end{array}$ & id adolesc & ence): optimisn & 1 sumscore (105 & 41), pessi & hism sum & score $(85,124)$, & gender $(3,1), \mathrm{pe}$ & \\
\hline
\end{tabular}




\section{Health quality of \\ life}

\section{Early adolescence group}

Optimism

Gender (girls/boys)

Parents marital status: Divorced parents (no/yes)

Family country background; One or two parents born outside Sweden (no/yes)

$\mathrm{R}^{2}$

\section{Pessimism}

Gender (girls/boys)

Parents marital status: Divorced parents (no/yes)

Family country background; One or two parents born outside Sweden (no/yes)

$\mathrm{R}^{2}$

Mid-adolescence group

\section{Optimism}

Gender (girls/boys)

Parents marital status: Divorced parents (no/yes)

Family country background; One or two parents born outside Sweden (no/yes)

$\mathrm{R}^{2}$

Pessimism

Gender (girls/boys)

Parents marital status: Divorced parents (no/yes)

Family country background; One or two parents born outside Sweden (no/yes)

$\mathrm{R}^{2}$
.24

.24

$-.07$

.10

$12.2 \%$

$-.26$

.25

$-.04$

.10

$<.001$

$<.001$

(.02)

.002

(.05)

.05

$12.9 \%$

$<.001$

$<.001$

.07

(.05)

.07
.37

.26

$-.11$

.02

$21.9 \%$

$-.36$

.24

$-.15$

(.08)

(.03)

(.04)

.01

(.09)
$<.001$

$<.001$

.01

$<.001$

$<.001$

$<.001$

.49

.78 


\section{Table 5}

The odds ratio with 95\% confidence intervals for high HRQOL (above mean) by quartil of optimism and pessimism in early adolescence group and Mid-adolescence group.

Early adolescence group Mid-adolescence group

\begin{tabular}{llllll}
$\mathrm{OR}^{\mathrm{a}}$ & $95 \% \mathrm{CI}$ & $\mathrm{P}$ & $\mathrm{OR}^{\mathrm{a}}$ & $95 \% \mathrm{CI}$ & $\mathrm{P}$ \\
\hline
\end{tabular}

Levels of OPTIMISM

Crude

Quartiel 1 - Low

Quartiel 2

Quartiel 3

Quartiel 4 - High

$\begin{array}{cccccc}1.0 & - & & 1.0 & - & \\ 1.59 & (0.80 ; 3.16) & .19 & 1.21 & (0.62 ; 2.37) & .57 \\ 2.34 & (1.27: 3.87) & .01 & 1.72 & (1.02: 2.88) & .014 \\ 4.02 & (2.35: 6.88) & <.001 & 2.63 & (1.50: 4.60) & <.001\end{array}$

Adjusted for gender

Quartiel 1 - Low

$1.0-\quad-\quad 1.0$

Quartiel 2

1.54

$(0.77 ; 3.07)$

.22

1.28

$(0.64 ; 2.55) \quad .48$

Quartiel 3

2.22

$(1.27: 3.86) \quad .01$

2.10

$(1.22: 3.61) \quad .01$

Quartiel 4 - High

3.97

$(2.31: 6.83)<.001$

3.97

$(1.76: 5.67)<.001$

Adjusted for gender, family country background and divorced parents

Quartiel 1 - Low

Quartiel 2

Quartiel 3

Quartiel 4 - High
1.0

1.57

2.09

3.80

$(0.77 ; 3.19)$

.21

1.0

1,24

$(0.61 ; 2.52) \quad .55$

$(1.18: 3.70)<.001 \quad 1.97$

$(1.18: 3.70) \quad .017$

$(2.18: 6.60)<.001$

3.09

$(2.18: 6.60)<.001$

Levels of PESSIMISM

Crude

Quartiel 1 - Low

Quartiel 2

Quartiel 3

Quartiel 4 - High

$\begin{array}{cccccc}3.30 & (1.73 ; 6.28) & <.001 & 4.69 & (1.74 ; 5.44) & <.001 \\ 1.84 & (0.96: 3.52) & .07 & 5.35 & (1.81 ; 6.23) & <.001 \\ 2.28 & (1.11: 4.66) & .02 & 1.97 & (0.98 ; 4.00) & 0.06 \\ 1.0 & - & & 1.0 & - & \end{array}$

Adjusted for gender

Quartiel 1 - Low

Quartiel 2

3.36

$(1.76 ; 6.44)<.001$

4.70

$(2.23 ; 9.91)<.001$

Quartiel 3

Quartiel 4 - High

1.90

$(0.98: 3.67) \quad .06$

5.34

$(2.44 ; 11.79)<.001$

2.32

$(1.13: 4.78) \quad .02$

1.97

$(0.97 ; 4.00) \quad 0.06$

Adjusted for gender, family country background and divorced parents

Quartiel 1 - Low

Quartiel 2

Quartiel 3

Quartiel 4 - High

$\begin{array}{cccccc}3.36 & (1.67 ; 6.65) & <.001 & 4.62 & (2.07 ; 10.31) & <.001 \\ 1.92 & (0.98: 3.80) & .06 & 4.75 & (2.05 ; 11.01) & <.001 \\ 2.09 & (0.99: 4.41) & .05 & 1.75 & (0.82 ; 3.71) & 0.06 \\ 1.0 & - & & 1.0 & - & \end{array}$

${ }^{\mathrm{a}}$ Association were analysed using logistic regression, $\mathrm{p}<.05$. 
